\title{
Ironing Out the Wrinkles in Host Defense: Interactions between Iron Homeostasis and Innate Immunity
}

\author{
Lijian Wang ${ }^{a, c}$ Bobby J. Cherayil ${ }^{a, b}$ \\ ${ }^{a}$ Mucosal Immunology Laboratory, Massachusetts General Hospital, Charlestown, Mass., bepartment of Pediatrics, \\ Harvard Medical School, and ' Department of Nutrition, Harvard School of Public Health, Boston, Mass., USA
}

\section{Key Words}

Iron homeostasis $\cdot$ Macrophage $\cdot$ Inflammation

\begin{abstract}
Iron is an essential micronutrient for both microbial pathogens and their mammalian hosts. Changes in iron availability and distribution have significant effects on pathogen virulence and on the immune response to infection. Recent advances in our understanding of the molecular regulation of iron metabolism have shed new light on how alterations in iron homeostasis both contribute to and influence innate immunity. In this article, we review what is currently known about the role of iron in the response to infection.
\end{abstract}

Copyright $\odot 2009$ S. Karger AG, Basel

'But Iron - Cold Iron - is master of them all.' Rudyard Kipling

\section{Introduction}

Kipling probably did not have iron homeostasis in mind when he expressed the sentiment quoted above, but what he held to be true of military conflict also applies to the battle between microbial pathogens and their mammalian hosts. Eukaryotic cells and most prokaryotic organisms require iron in order to maintain the function of numerous biological processes. Not surprisingly, intense competition for iron between host and pathogen often occurs during the course of infectious disease, and the availability of this precious metal can have a significant impact on both pathogen virulence and host anti-microbial defenses. Several recent reviews have discussed the mechanisms used by microbes to acquire iron during infection of higher organisms, and the importance of this process in the expression of virulence characteristics [14]. Here, we focus on how the mammalian immune system manipulates iron levels in order to limit the multiplication of pathogenic organisms, and how changes in iron metabolism can influence the innate immune response to infection.

\section{Overview of Mammalian Iron Metabolism and Its Regulation}

Plasma and cellular iron levels are tightly regulated in order to ensure availability for essential functions while avoiding the toxicity associated with excess. The last $4-5$ years have seen significant advances in our understanding, at the molecular level, of how this delicate balance is maintained in mammals (fig. 1) [5, 6]. Plasma iron is derived from two important sources. A minor proportion (1-2 $\mathrm{mg} /$ day) is absorbed from the diet by duodenal enterocytes, while the majority (23-24 mg/day) is derived from the destruction of senescent erythrocytes by the

\section{KARGER \\ Fax +4161306 1234 \\ E-Mail karger@karger.ch}

www.karger.com
(C) 2009 S. Karger AG, Basel

$1662-811 X / 09 / 0015-0455 \$ 26.00 / 0$

Accessible online at:

www.karger.com/jin
Dr. Bobby J. Cherayil

Pediatric Gastroenterology Unit

Massachusetts General Hospital

Building 114, 16th, Street, Charlestown, MA 02129 (USA)

Tel. +1 617726 4170, Fax +1 617726 4172, E-Mail cherayil@helix.mgh.harvard.edu 
Fig. 1. Regulation of iron homeostasis in mammals. Iron $(\mathrm{Fe})$ derived either from the destruction of red blood cells (RBC) or from dietary sources in the intestine is transported into the cytosol of macrophages and enterocytes, respectively, via the transporter Nramp2. The metal can be used for cellular metabolism, stored in complex with ferritin, or exported by FPN into the circulation, where it binds to Tf. The hepatocyte-derived peptide hepcidin, the expression of which is upregulated by iron overload and inflammation and downregulated by iron deficiency, anemia and hypoxia, plays a central role in iron homeostasis by binding to FPN and inducing its internalization and degradation.

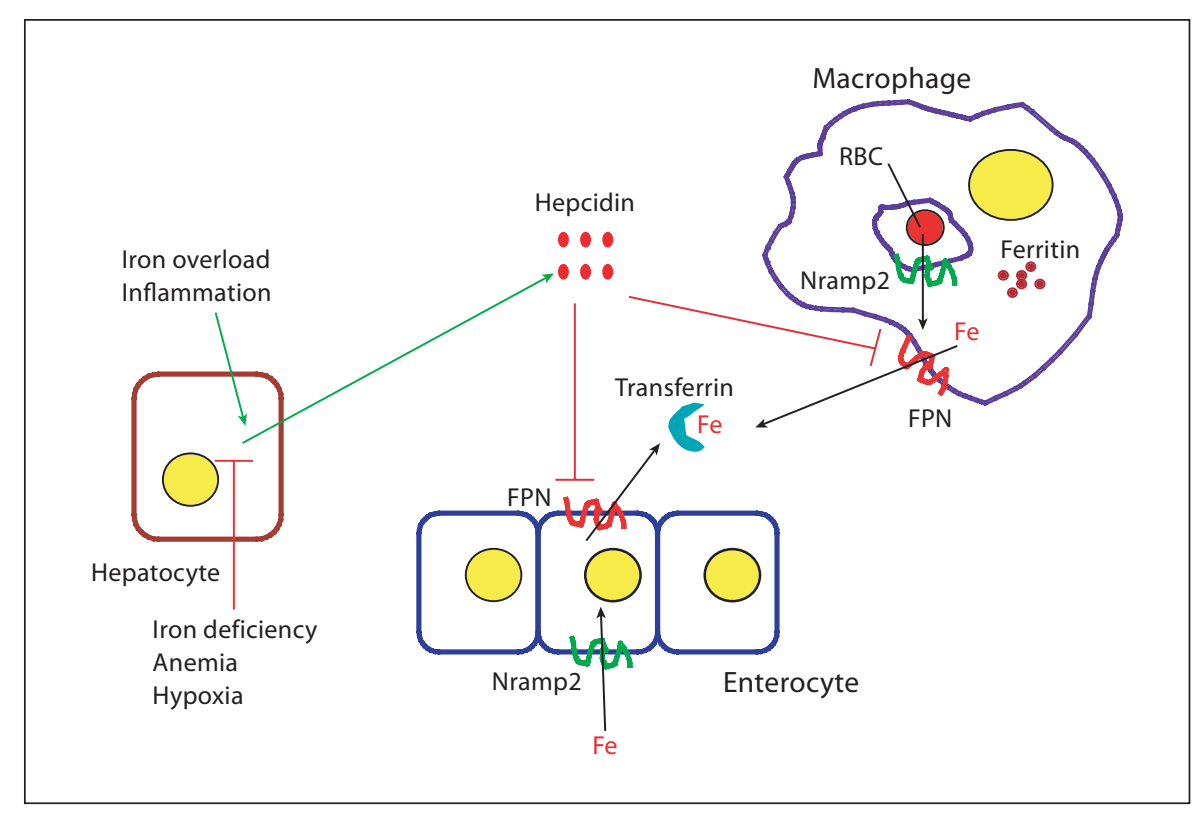

macrophages of the reticuloendothelial system. Dietary iron is transported across the apical membrane of the enterocyte by the transporter Nramp2 (also known as Slc11a2 and DMT1), after reduction to the ferrous state by an apical membrane expressed ferrireductase if required. The absorbed iron is released into the circulation at the basolateral surface of the enterocyte through the export protein ferroportin (FPN, also known as Slc40a1, MTP1 and IREG1). After oxidation to the ferric form by either hephaestin (located on the enterocyte plasma membrane) or circulating ceruloplasmin, the iron is transported in complex with the protein transferrin (Tf) to sites of utilization. Cells take up Tf-bound iron by means of the ubiquitously expressed Tf receptor 1 (TfR1). Iron derived from the breakdown of aged red blood cells, as well as that released from internalized Tf-TfR1 complexes, is moved via Nramp2 from the lumen of the endosome or phagosome into the cytosol, where it can be used for cellular functions or stored in the form of insoluble ferritin. In the phagocytes of the reticuloendothelial system, iron can also be pumped out into the circulation by plasma membrane-expressed FPN.

A key aspect of iron homeostasis is the regulation of FPN expression, which controls the amount of the metal released into the plasma from duodenal enterocytes after dietary absorption and from macrophages involved in recycling iron from erythrocytes. FPN expression is regulated posttranslationally by the circulating hepatocyte-derived peptide hormone hepcidin, which binds to FPN and induces its internalization and lysosomal degradation [7]. Production of hepcidin, in turn, is regulated by a number of factors, including those that reflect body iron status and requirements $[8,9]$. In general, conditions associated with increased iron demand such as iron deficiency anemia and hypoxia inhibit production of hepcidin, thereby allowing higher FPN expression and increased release of iron from the gut and reticuloendothelial system. Conversely, elevated body iron stores, as well as infections and inflammatory conditions, lead to increased hepcidin production, with consequent downregulation of FPN expression and inhibition of iron release from macrophages and enterocytes. Thus, proper functioning of the hepcidin-FPN axis ensures that the amounts of iron entering the circulation are appropriate to body stores and demands.

Intracellular free iron concentrations depend on circulating levels, but are also controlled by regulated changes in expression of ferritin and TfR1. The expression of these proteins is controlled posttranscriptionally via iron response elements that are found in the $5^{\prime}$-untranslated region of the ferritin mRNA and in the $3^{\prime}$-untranslated region of the TfR 1 mRNA. Under conditions of low cytosolic iron, trans-acting regulatory proteins (IRE-binding proteins or IRPs) bind to the IREs and inhibit mRNA translation in the case of ferritin and promote mRNA stability in the case of TfR1 $[10,11]$. These changes lead to decreased ferritin expression and increased TfR 1 expression, both of which facilitate an increase in cytosolic iron levels. The IRE-IRP system thus helps to maintain 
cellular iron homeostasis by modulating ferritin and TfR1 expression.

Why should the immunologist care about iron homeostasis? Firstly, changes in iron distribution and availability occur during the response to infection, and some of these alterations may influence pathogen growth. They can also have significant effects on the responses of cells such as macrophages and epithelial cells. Secondly, chronic disorders of iron metabolism can alter susceptibility to infectious disease. Iron overload caused by dietary excess, abnormal hemolysis, or inherited disorders of metabolism predisposes to infections such as salmonellosis, tuberculosis and malaria [12-15]. On the other hand, iron deficiency can provide relative resistance to certain infections such as tuberculosis and malaria, and iron supplements have been shown to counteract this effect [16-18]. Iron-dependent effects on pathogen virulence and host immunity have been suggested as explanations for these altered susceptibilities, but the underlying mechanisms remain to be fully understood. It is clear that there are a number of cross-connections between iron homeostasis and normal functioning of the immune system. Understanding the molecular details of these interactions will not only shed light on basic strategies of immune defense and immunoregulation, but will also help to explain the increased susceptibility to infection that often accompanies diseases of iron metabolism $[19,20]$. In the sections that follow, we will first discuss the role of iron deprivation in protection against infection, and then go on to review the various ways in which abnormalities of iron metabolism can influence innate immunity.

\section{Iron Deprivation as an Antimicrobial Defense Strategy}

Given the importance of iron in microbial growth and virulence, it is not surprising that mammals have evolved strategies to restrict the availability of the metal to infecting pathogens. These strategies range from a global decrease in circulating iron levels as a result of modulation of the hepcidin-FPN axis to the expression of molecules that specifically compete with microbial iron acquisition mechanisms.

\section{Iron Sequestration by Modulation of the}

Hepcidin-FPN Axis

A potent stimulus for the induction of hepcidin expression in the liver is the cytokine IL-6. This aspect of IL-6 function may involve direct transcriptional upregu- lation of the hepcidin gene or, as has been shown recently, may be mediated by hepatocyte-derived bone morphogenetic proteins acting in a paracrine or autocrine manner on bone morphogenetic protein receptors and the coreceptor hemojuvelin [21-24]. As a result of the ability of IL-6 to increase hepcidin expression, and the well-known involvement of this cytokine in inflammation, many acute and chronic infectious and inflammatory processes are accompanied by a rise in circulating hepcidin levels. The consequent downregulation of FPN expression leads to hypoferremia as a result of iron sequestration within phagocytes and enterocytes. Although the decrease in circulating iron contributes to the anemia of chronic disease, it is also thought to have a protective effect against infection by depriving pathogens of a muchneeded nutrient $[8,25]$. Experimental evidence in support of this idea comes from a mouse model of extracellular Escherichia coli infection in which gene expression profiling of the bacterial pathogen indicated an iron-deprived state [26]. The recent identification of reagents that specifically inhibit hepcidin expression [22, 27], and the availability of various transgenic mouse strains with altered hepcidin and FPN expression or function [28-31] should now provide for more rigorous investigation of the role of hepcidin-mediated iron sequestration in antimicrobial defense.

\section{Expression of Macrophage Iron Transporters}

The macrophage is a favored site of long-term residence by intracellular pathogens such as Salmonella, $M y$ cobacteria, Leishmania and Chlamydia. Alterations in intramacrophage iron content and distribution would be expected to influence the growth of such organisms and could be considered to constitute part of the phagocytic antimicrobial armamentarium. Indeed, one of the earliest infectious disease susceptibility genes to be identified in the mouse was Nramp1 (Slc11a1), which encodes a phagosomal divalent metal ion transporter [32]. Although there is some controversy over the directionality of metal transport by the Nramp1 protein, current evidence favors the idea that it pumps iron and manganese out of the phagosomal compartment into the cytosol, thereby inhibiting the growth of pathogens that live within the phagosome $[3,33,34]$. Besides the direct effects of iron deprivation on intracellular pathogen survival and growth, Nrampl-mediated changes in iron distribution may also influence macrophage functions such as the production of inflammatory cytokines and reactive oxygen and nitrogen radicals [35]. The importance of Nramp1 function is highlighted by the fact that mice with wild- 
type alleles of Nramp1 are able to restrict the early intramacrophage multiplication of organisms such as Salmonella, Leishmania and Mycobacteria, allowing the development of effective adaptive immunity that eliminates or significantly contains these infections. In contrast, mice with homozygous inactivating mutations in Nramp1 suffer from uncontrolled growth of the pathogen and ultimately succumb. The role of the Nramp1 gene in human immune defense and susceptibility to infection is not as clear-cut as in the mouse. While an association between polymorphisms in Nrampl and susceptibility to tuberculosis or leprosy has been demonstrated in some studies, it has not been replicated in others, and the effect may be restricted to specific populations or geographic areas [36, 37].

Recent work from our laboratory and several other groups has implicated another macrophage iron transporter, the iron efflux protein FPN, in the control of intracellular pathogen growth. We found that increased expression of FPN inhibited the growth of Salmonella typhimurium in epithelial cells and macrophages, whereas hepcidin-induced downregulation of FPN favored multiplication of the bacteria [38]. The pattern of bacterial gene expression in the FPN-overexpressing cells was consistent with an iron-deprived state, suggesting that FPN-mediated iron efflux lowered iron levels within the Salmonella-containing vacuolar compartment. Similarly, iron uptake and growth of Mycobacterium tuberculosis was found to be inhibited in monocyte-macrophages from patients with $\mathrm{HFE}$-associated hemochromatosis, a disorder of iron homeostasis in which FPN expression is increased on these cells [39]. However, recent in vivo experiments show that mice with disruption of the Hfe gene, which results in abnormalities similar to human $H F E$-associated hemochromatosis, are more susceptible to Mycobacterium avium infection than wild-type animals [40]. Effects of altered FPN expression and function on the intracellular growth of Chlamydia and Legionella have also been demonstrated [41]. Increased expression of FPN on macrophages has been shown to occur when these cells are infected with Salmonella or Mycobacteria [42, 43], and similar upregulation also occurs in response to treatment with interferon- $\gamma$ [44]. Putting these various findings together, it would appear that elevation of FPN on macrophages may help to limit early pathogen growth within these cells by lowering intracellular iron concentrations. However, it must be borne in mind, as discussed earlier, that infection in vivo is associated with a rise in circulating hepcidin levels, which would result in downregulation of FPN. The net effect on macrophage FPN expression in the animal, and the consequent influence on intracellular pathogen multiplication, would thus depend on the balance between the opposing forces represented by hepcidin on the one hand and macrophage activation mediated by microbial molecules or interferon- $\gamma$ on the other. Further studies in animal models of infection are clearly required to clarify this issue.

\section{Expression of Secreted Iron-Binding Proteins}

Lactoferrin is a Tf-related glycoprotein that binds ferric iron with high affinity. It is secreted constitutively by epithelial cells lining the mammary gland and the respiratory and gastrointestinal tracts, and is present in high concentrations in milk and mucosal secretions. It is also a constituent of neutrophil granules and is released at sites of inflammation. It has long been considered an important factor in innate immunity, particularly at mucosal surfaces. This role is partly based on its ability to sequester iron from infectious microorganisms, but lactoferrin has also been shown to have defensin-like antimicrobial effects, and to modulate inflammatory responses by both iron-binding-dependent and -independent mechanisms $[45,46]$. Although the ability of exogenously administered lactoferrin to inhibit bacterial growth has been demonstrated in a number of in vitro and in vivo assays [19], its physiologic role in immune defense is not clear. Mice with homozygous disruption of the lactoferrin gene have no major abnormalities in either iron homeostasis or the immune system, and are able to handle infections with Staphylococcus aureus, Pseudomonas aeruginosa and $M$. tuberculosis as well as wild-type animals [19, 47, 48].

One of the mechanisms used by bacteria to acquire iron from their hosts involves the production of siderophores, small secreted molecules that have an affinity for ferric iron comparable to Tf and lactoferrin [49]. The production of siderophores, other molecules involved in iron transport, and some toxins such as shiga toxin and diphtheria toxin, is controlled by the iron-binding transcription factor ferric uptake regulator (Fur), which represses expression of the relevant genes when bacterial ferrous levels are high. The repression is relieved under conditions of low iron availability, allowing increased transcription of the Fur-regulated genes [50]. During in vivo bacterial infection, Fur-regulated genes, including those involved in siderophore biosynthesis, have been shown to be expressed at high levels in sites such as the peritoneal cavity and spleen, in part because iron levels are low in these areas whereas expression in iron-replete locations 
such as the intestinal lumen is low [51]. The production of siderophores in response to ambient iron concentrations facilitates survival of microbial pathogens in the low-iron environment of mammalian serum and tissue. However, in the never-ending battle for iron between pathogen and host, the immune system counters by producing siderocalin (also known as lipocalin 2 and neutrophil gelatinase-associated lipocalin, NGAL), a protein that is upregulated as part of the acute-phase response to infection, and that binds specifically to some siderophores to disrupt pathogen iron acquisition $[52,53]$. Siderocalin is secreted by neutrophils, macrophages and other cell types following infection by a number of different organisms, and in some cases Toll-like receptors (TLRs) have been shown to be involved in this response [42, 54-57]. Siderocalin knockout mice have compromised immunity to pathogenic E. coli and to M. tuberculosis, displaying elevated tissue bacterial numbers and decreased survival following infection with these organisms [54, 58, 59]. In keeping with these in vivo abnormalities, neutrophils and alveolar epithelial cells from the mutant animals are impaired in their in vitro ability to kill the E. coli and M. tuberculosis, respectively. Studies in humans also suggest a potential role for siderocalin in protection against bacterial pathogens. In an analysis of $M$. tuberculosis infection among contacts of individuals with active pulmonary tuberculosis, the incidence of infection was inversely correlated with circulating neutrophil numbers and serum levels of neutrophil antimicrobial peptides, including siderocalin [60]. Further illustration of the importance of siderocalin, as well as evidence for pathogen-host coevolution, is provided by the finding that several pathogenic bacteria have developed mechanisms to evade the inhibitory activity of this protein by the production of multiple and/or modified siderophores. Thus, in contrast to nonpathogenic enteric bacteria, which produce a siderophore that can be neutralized by siderocalin, Salmonella secretes a glucosylated siderophore, salmochelin, that is not bound by siderocalin [49, 61]. Similarly, M. tuberculosis expresses multiple forms of its siderophore, carboxymycobactin, which vary in the length of their fatty acid side chains, and only some of these forms are bound by siderocalin [53].

Siderocalin may also have functions independent of its ability to sequester bacterial siderophores. In the unliganded state, it has been reported to reduce intracellular free iron by unclear mechanisms, while in certain situations it may actually deliver iron to cells $[62,63]$. The physiologic significance of these observations is yet to be demonstrated, but one could speculate that production of siderocalin may help to counteract the effects of hepcidin-mediated downregulation of FPN and the attendant increase in intracellular iron.

\section{Effects of Altered Iron Homeostasis on Innate Immunity}

As discussed in an earlier section, acute changes in circulating and intracellular iron levels can occur during infection as a result of altered expression of hepcidin and FPN. More chronic changes are observed in the states of disturbed iron homeostasis associated with nutritional iron deficiency, hemolytic anemias and the group of inherited iron overload disorders known as hereditary hemochromatosis. Although the pathophysiology of these conditions varies, a feature common to all of them (with the exception of type IV hemochromatosis) is suppression of hepcidin expression, with consequent upregulation of FPN on macrophages and a decrease in the intracellular levels of iron in these cells [8, 9, 64-66]. Type IV hemochromatosis (ferroportin disease) is characterized by missense mutations in FPN that result in either increased or decreased levels of intramacrophage iron depending on whether the mutation inactivates iron export function or not [31].

What effect do the alterations in iron homeostasis described above have on cells of the innate immune system, particularly macrophages? This question is of both immunological interest and clinical relevance since many chronic disturbances of iron handling are associated with altered susceptibility to infectious disease [12-18]. In general terms, changes in the intracellular levels of free iron have been shown to alter patterns of cellular gene expression, with iron loading eliciting the effects of oxidative stress and iron depletion those of hypoxia [67]. It is reasonable to expect that such effects would have an impact on the behavior of cells of the immune system. To address the issue more specifically, it is necessary to understand the ways in which iron can influence those cellular functions that contribute most significantly to innate immune responses.

\section{Iron and $N F-\kappa B$}

$\mathrm{NF}-\kappa \mathrm{B}$ is a transcription factor that plays a key role in the expression of genes involved in various aspects of innate and adaptive immunity $[68,69]$. It can be activated by signals delivered through cell surface receptors or by a variety of intracellular or extracellular stresses. Intracellular free iron has been implicated in a number of these 
activation events, usually because of its ability to catalyze the generation of reactive oxygen species [67]. Reactive oxygen species production has been linked to the activation of NF- $\kappa \mathrm{B}$, although there is considerable controversy about the generality of this notion and the precise mechanisms involved [70].

There is a fairly extensive (albeit older) literature demonstrating various effects of iron and iron chelators on macrophage function, some of which have involved NF$\kappa \mathrm{B}$. More recent papers have sought to clarify the underlying mechanisms. In one experimental model, addition of ferrous sulfate to cultured hepatic macrophages has been shown to activate NF- $\kappa \mathrm{B}$ and to lead to the production of the proinflammatory cytokine $\mathrm{TNF} \alpha$, a process that has been suggested to contribute to the pathogenesis of liver damage in states of iron overload [71]. The mechanism appears to involve an effect of iron upstream of IкB $\alpha$ degradation, and is associated with an increase in reactive oxygen species levels [71, 72]. Furthermore, treatment of macrophages with LPS has been shown to result in a rapid, transient elevation of intracellular free-iron levels that precedes NF- $\kappa \mathrm{B}$ activation, thus placing these observations in the context of physiologic macrophage activation [73].

In keeping with the results described above, reduction of free intracellular iron generally inhibits NF- $\kappa \mathrm{B}$ activation. This conclusion is based on numerous experiments with iron chelators. In addition, there is a limited amount of data indicating that reduced intracellular iron associated with states of altered iron homeostasis also has inhibitory effects on activation of NF- $\kappa B$. These data come from studies of heme oxygenase-1 (HO-1), an enzyme that plays an important role in the recycling of iron from senescent erythrocytes by cleaving the porphyrin ring of heme to release ferrous iron while generating biliverdin and carbon monoxide [74]. HO-1, which is upregulated in macrophages and other cells during infection [42], also has anti-inflammatory effects that have been attributed to the ability of carbon monoxide to modulate p38 kinase signaling and TLR activation [75]. However, there is recent evidence to suggest that some of these effects may be related to HO-1-mediated changes in intracellular freeiron levels that impact on the activity of NF- $\kappa B$. Specifically, increased expression or activity of HO-1 has been shown to lead to a decrease in intracellular iron because of elevated ferritin expression and enhanced iron efflux. These changes are associated with impaired phosphorylation of the RelA subunit of NF- $\kappa \mathrm{B}$ and a corresponding decrease in transcriptional activity. The attenuation of both RelA phosphorylation and NF- $\kappa \mathrm{B}$ activity are mimicked by deferoxamine treatment, implicating changes in intracellular iron in the effects of HO-1 [76, 77]. One of the consequences of HO-1-dependent regulation of NF$\kappa \mathrm{B}$ activity is exaggerated TNF $\alpha$-induced expression of adhesion molecules on endothelial cells of HO-1-deficient mice, an abnormality that may contribute to the hyperinflammatory phenotype of these animals [74, 77].

\section{Iron and the Hypoxia-Inducible Factors}

The hypoxia-inducible factors (HIFs) are a family of heterodimeric helix-loop-helix transcription factors that play important roles in the cellular response to hypoxia [78]. Each member of the family, of which HIF-1 is representative and most studied, consists of an unstable $\alpha$-subunit and a stable $\beta$-subunit. Under normoxic conditions, HIF- $1 \alpha$ is hydroxylated on specific proline residues, a modification that creates a binding site for the von Hippel-Lindau protein and that promotes von Hippel-Lindau protein-dependent targeting for proteasomal degradation. The hydroxylation is carried out by a family of prolyl hydroxylase domain proteins, whose activity is dependent on oxygen and iron. Accordingly, under conditions of hypoxia or low intracellular iron concentrations, prolyl hydroxylase domain protein activity is decreased, HIF$1 \alpha$ is stabilized, and the resultant accumulation of HIF-1 leads to the transcriptional activation of a large number of genes involved in erythropoiesis, angiogenesis and glycolysis. In addition to these functions, HIF-1 also plays an important role in the innate immune response, as revealed by analysis of mice with a myeloid cell-specific disruption of the HIF- $1 \alpha$ gene. These studies revealed a number of abnormalities in the response to infection in the knockout animals or cells, including increased susceptibility to Gram-negative and Gram-positive bacterial pathogens, and decreased production of antimicrobial peptides, inflammatory cytokines, nitric oxide and lysosomal proteases [79-81]. While there is little doubt that the hypoxic conditions prevailing in infected and damaged tissue constitute one of the major stimuli for HIF- $1 \alpha$ stabilization [79], hypoxia-independent effects of the infecting microorganism itself also contribute significantly to this process. Such effects involve NF- $\mathrm{B}$-dependent transcriptional upregulation of HIF-1 $\alpha$ [82], as well as stabilization of HIF- $1 \alpha$ as a result of bacteria-induced lowering of intracellular iron. Recent work has shown that the mechanism responsible for the latter phenomenon probably involves siderophores secreted by the infecting pathogen [83]. Thus, changes in intracellular iron that accompany infection provide a trigger for the deployment of antimicrobial defense mechanisms via the stabilization of HIF-1 $\alpha$. 
Fig. 2. Interconnections between iron homeostasis and innate immunity in the response to infection. Infection leads to altered intra- and extracellular iron (Fe) concentrations as a consequence of changes in the expression of FPN, heme oxygenase and siderocalin, or as a result of the effects of bacterial siderophores. Changes in iron concentrations can have direct effects on bacterial growth, and can also influence host gene expression via modulation of the function of transcription factors such as NF- $\kappa \mathrm{B}$ and HIF- $1 \alpha$.

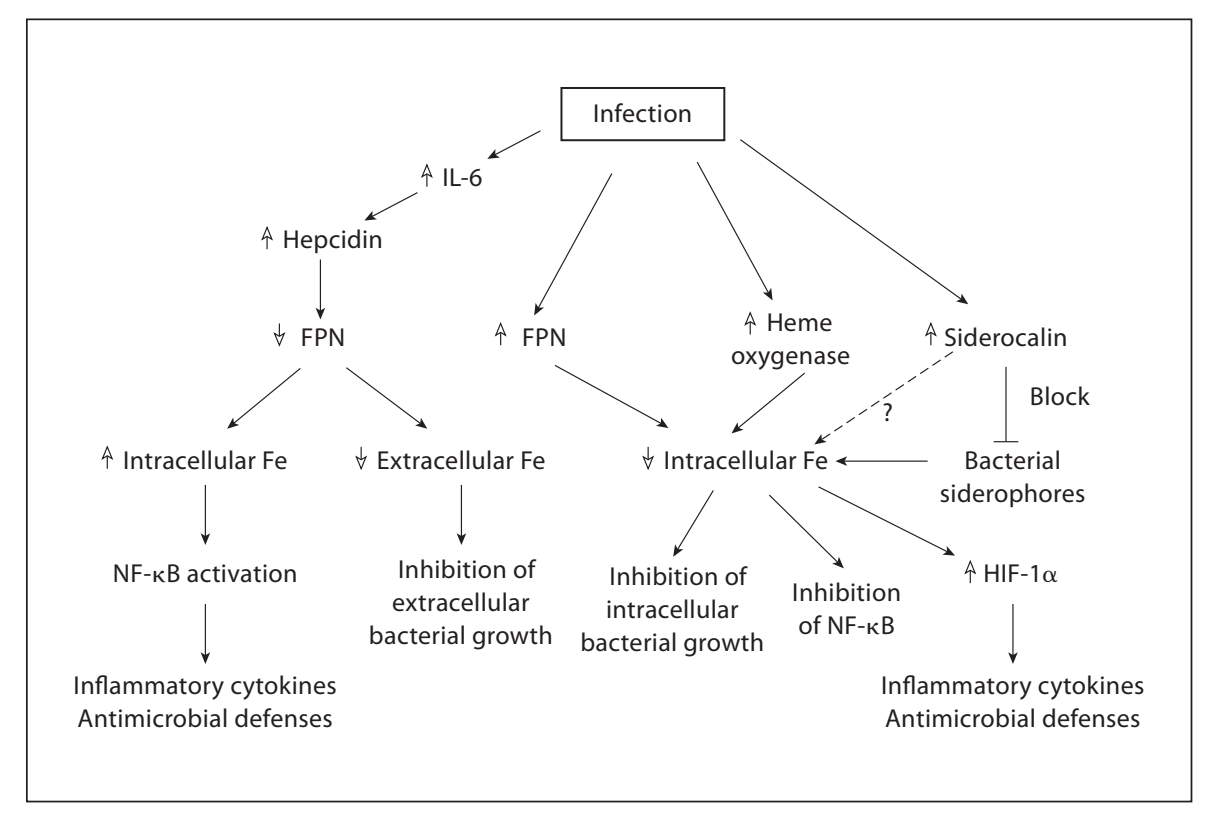

\section{Other Effects of Iron}

Although reduction of intracellular iron inhibits NF$\kappa \mathrm{B}$-dependent responses, iron chelation has been shown to activate MAP kinases and to promote the production of inflammatory mediators in intestinal epithelial cells [84-86]. The mechanism underlying this effect and its potential relationship to stabilization of HIF- $1 \alpha$ remain to be elucidated.

Work from our laboratory has been directed at characterizing abnormalities of innate immunity in disorders of iron homeostasis. The results of our recent studies have indicated that macrophages from $\mathrm{Hfe}$-deficient mice, a model of human type I hemochromatosis, are impaired in their ability to translate TNF $\alpha$ and IL- 6 mRNAs in response to TLR4 stimulation [87]. The defect was found to be related to the low intracellular iron concentration in the $H f e$ knockout macrophages, a consequence of the elevated FPN expression on these cells caused by low circulating hepcidin levels. The reduction of macrophage inflammatory cytokine production observed in vitro correlated with in vivo abnormalities in the response to oral infection with Salmonella, including attenuated enterocolitis and an increase in tissue pathogen burden. These observations have revealed a previously unappreciated role for intracellular iron in regulating cytokine biosynthesis that has a clear impact on the response to infection. The findings also provide a potential explanation for the increased susceptibility of individuals with type I hemochromatosis to pathogens such as Salmonella, Vibrio and Yersinia [20, 88].

\section{Conclusion}

The research summarized in the preceding pages highlights the many interconnections between the molecules involved in iron homeostasis and innate immunity (fig. 2). Many of these interactions appear to oppose each other with respect to their effects on both iron concentrations and the immune response, a circumstance that may reflect either the operation of self-regulating mechanisms or the incompleteness of available information. It is also likely that not all the pathways illustrated actually play a role in any given situation. Additional work is required to clarify these issues.

What is fairly well established is that changes in iron availability have a strong influence on pathogen growth and virulence, and that iron deprivation by various means is an important component of first-line defense against infection. At the same time, it is becoming increasingly clear that alterations in iron levels also have a definite impact on the functioning of immunologically relevant cells. One concept that may be emerging from the accumulating evidence is that significant deviations from the norm in intracellular and extracellular iron concentrations may function not only as an antimicrobial defense mechanism but also as a 'danger' signal that can act in conjunction with more traditional microbial pattern recognition receptors to trigger appropriate protective responses. For instance, the rise in circulating hepcidin levels that accompanies infection leads to downregulation 
of FPN expression, with the consequent intracellular sequestration of iron serving the dual purpose of depriving extracellular pathogens of iron while promoting macrophage inflammatory responses. Similarly, a fall in intracellular iron may indicate the presence of bacterial siderophores and, by inducing HIF- $1 \alpha$-dependent alterations in gene expression, may complement the function of other sensors of infection. Further clarification of the mechanisms involved in the effects of iron on the immune system will provide a framework for understand- ing the immunological consequences of disordered iron homeostasis, and for developing novel approaches to controlling immune function based on manipulating iron levels.

\section{Acknowledgments}

We are grateful to Drs. Jonathan Kagan, Shiv Pillai, Hai Ning Shi and Marianne Wessling-Resnick for their helpful comments on the manuscript.

\section{References}

1 Rodriguez GM: Control of iron metabolism in Mycobacterium tuberculosis. Trends Microbiol 2006; 14:320-327.

$\checkmark 2$ Miethke M, Marahiel MA: Siderophorebased iron acquisition and pathogen control. Microbiol Mol Biol Rev 2007;71:413-451.

- 3 Huynh C, Andrews NW: Iron acquisition within host cells and the pathogenicity of Leishmania. Cell Microbiol 2008;10:293300.

4 Sutak R, Lesuisse E, Tachezy J, Richardson DR: Crusade for iron: iron uptake in unicellular eukaryotes and its significance for virulence. Trends Microbiol 2008;16:261-268.

5 Andrews NC, Schmidt PJ: Iron homeostasis. Annu Rev Physiol 2007;69:69-85.

6 De Domenico I, McVey Ward D, Kaplan J: Regulation of iron acquisition and storage: consequences for iron-linked disorders. Nat Rev Mol Cell Biol 2008;9:72-81.

7 Nemeth E, Tuttle MS, Powelson J, Vaughn MB, Donovan A, Ward DM, Ganz T, Kaplan J: Hepcidin regulates cellular iron efflux by binding to ferroportin and inducing its internalization. Science 2004;306:2090-2093.

8 Nemeth E: Iron regulation and erythropoiesis. Curr Opin Hematol 2008;15:169-175.

9 Muckenthaler MU: Fine tuning of hepcidin expression by positive and negative regulators. Cell Metab 2008;8:1-3.

10 Rouault TA: The role of iron regulatory proteins in mammalian iron homeostasis and disease. Nat Chem Biol 2006;2:406-414.

11 Muckenthaler MU, Galy B, Hentze MW: Systemic iron homeostasis and the iron-responsive element/iron-regulatory protein (IRE/ IRP) regulatory network. Annu Rev Nutr 2008;28:197-213.

-12 Moyo VM, Gangaidzo IT, Gordeuk VR, Kiire CF, Macphail AP: Tuberculosis and iron overload in Africa: a review. Cent Afr J Med 1997;43:334-339.

13 Magnus SA, Hambleton IR, Moosdeen F, Serjeant GR: Recurrent infections in homozygous sickle cell disease. Arch Dis Child 1999;80:537-541.
14 Wanachiwanawin $\mathrm{W}$ : Infections in $\mathrm{E} \beta$ thalassemia: J Pediatr Hematol Oncol 2000;22: 581-587.

15 Gangaidzo IT, Moyo VM, Mvundura E, Aggrey G, Murphree NL, Khumalo H, Saungweme T, Kasvosve I, Gomo ZA, Rouault T, Boelaert JR, Gordeuk VR: Association of pulmonary tuberculosis with increased dietary iron. J Infect Dis 2001;184:936-939.

16 Murray MJ, Murray AB, Murray MB, Murray $C J$ : The adverse effect of iron repletion on the course of certain infections. Br Med J 1978;2:1113-1115.

17 Nyakeriga AM, Troye-Blomberg M, Dorfman JR, Alexander ND, Bäck R, Kortok M, Chemtai AK, Marsh K, Williams TN: Iron deficiency and malaria among children living on the coast of Kenya. J Infect Dis 2004; 190:439-447.

$\checkmark 18$ Sazawal S, Black RE, Ramsan M, Chwaya HM, Stoltzfus RJ, Dutta A, Dhingra U, Kabole I, Deb S, Othman MK, Kabole FM: Effects of routine prophylactic supplementation with iron and folic acid on admission to hospital and mortality in preschool children in a high malaria transmission setting: community-based, randomised, placebo-controlled trial. Lancet 2006;367:133-143.

19 Schaible UE, Kaufmann SH: Iron and microbial infection. Nat Rev Microbiol 2004;2: 946-953.

20 Doherty CP: Host-pathogen interactions: the role of iron. J Nutr 2007;137:1341-1344.

21 Babitt JL, Huang FW, Wrighting DM, Xia Y, Sidis Y, Samad TA, Campagna JA, Chung RT, Schneyer AL, Woolf CJ, Andrews NC, Lin HY: Bone morphogenetic protein signaling by hemojuvelin regulates hepcidin expression. Nat Genet 2006;38:531-539.

-22 Babitt JL, Huang FW, Xia Y, Sidis Y, Andrews NC, Lin HY: Modulation of bone morphogenetic protein signaling in vivo regulates systemic iron balance. J Clin Invest 2007;117: 1933-1939.

23 De Domenico I, Ward DM, Kaplan J: Hepcidin regulation: ironing out the details. J Clin Invest 2007;117:1755-1758.
24 Xia Y, Babitt JL, Sidis Y, Chung RT, Lin HY: Hemojuvelin regulates hepcidin expression via a selective subset of BMP ligands and receptors independently of neogenin. Blood 2008;111:5195-5204

25 Ganz T: Hepcidin - a peptide hormone at the interface of innate immunity and iron metabolism. Curr Top Microbiol Immunol 2006;306:183-198

26 Motley ST, Morrow BJ, Liu X, Dodge IL, Vitiello A, Ward CK, Shaw KJ: Simultaneous analysis of host and pathogen interactions during an in vivo infection reveals local induction of host acute phase response proteins, a novel bacterial stress response, and evidence of a host-imposed metal ion limited environment. Cell Microbiol 2004;6:849865.

27 Yu PB, Hong CC, Sachidanandan C, Babitt JL, Deng DY, Hoyng SA, Lin HY, Bloch KD, Peterson RT: Dorsomorphin inhibits BMP signals required for embryogenesis and iron metabolism. Nat Chem Biol 2008;4:33-41.

28 Nicolas G, Bennoun M, Devaux I, Beaumont C, Grandchamp B, Kahn A, Vaulont S: Lack of hepcidin gene expression and severe tissue iron overload in upstream stimulatory factor 2 (USF2) knock-out mice. Proc Natl Acad Sci USA 2001;98:8780-8785.

29 Roy CN, Mak HH, Akpan I, Losyev G, Zurakowski D, Andrews NC: Hepcidin anti-microbial peptide transgenic mice exhibit features of the anemia of inflammation. Blood 2007;109:4038-4044.

30 Zohn IE, De Domenico I, Pollock A, Ward DM, Goodman JF, Liang X, Sanchez AJ, Niswander L, Kaplan J: The flatiron mutation in mouse ferroportin acts as a dominant negative to cause ferroportin disease. Blood 2007;109:4174-4180.

-31 Johnson EE, Wessling-Resnick M: Flatiron mice and ferroportin disease. Nutr Rev 2007; 65:341-345.

- 32 Marquis JF, Gros P: Genetic analysis of resistance to infections in mice: $\mathrm{A} / \mathrm{J}$ meets C57BL6/J. Curr Top Microbiol Immunol 2008;321:27-57. 
-33 Fortier A, Min-Oo G, Forbes J, Lam-YukTseung S, Gros P: Single gene effects in mouse models of host: pathogen interactions. J Leukoc Biol 2005;77:868-877.

- 34 Cellier MF, Courville P, Campion C: Nramp1 phagocyte intracellular metal withdrawal defense. Microbes Infect 2007;9:1662-1670.

- 35 Blackwell JM, Goswami T, Evans CA, Sibthorpe D, Papo N, White JK, Searle S, Miller EN, Peacock CS, Mohammed H, Ibrahim M: Slc1la1 (formerly Nramp1) and disease resistance. Cell Microbiol 2001;3:773-784.

- 36 Abe T, Iinuma Y, Ando M, Yokoyama T, Yamamoto T, Nakashima K, Takagi N, Baba H, Hasegawa Y, Shimokata K: Nramp1 polymorphisms, susceptibility and clinical features of tuberculosis. J Infect 2003;46:215220.

- 37 Li HT, Zhang TT, Zhou YQ, Huang QH, Huang J: Slc1la1 (formerly Nrampl) gene polymorphisms and tuberculosis susceptibility: a meta-analysis. Int J Tuberc Lung Dis 2006;10:3-12.

- 38 Chlosta S, Fishman DS, Harrington L, Johnson EE, Knutson MD, Wessling-Resnick M, Cherayil BJ: The iron efflux protein ferroportin regulates the intracellular growth of Salmonella enterica. Infect Immun 2006;74: 3065-3067.

- 39 Olakanmi O, Schlesinger LS, Britigan BE: Hereditary hemochromatosis results in decreased iron acquisition and growth by $M y$ cobacterium tuberculosis within human macrophages. J Leukoc Biol 2007;81:195204.

-40 Gomes-Pereira S, Rodrigues PN, Appelberg $\mathrm{R}$, Gomes MS: Increased susceptibility to Mycobacterium avium in hemochromatosis protein HFE-deficient mice. Infect Immun 2008;76:4713-4719.

-41 Paradkar PN, De Domenico I, Durchfort N, Zohn I, Kaplan J, Ward DM: Iron depletion limits intracellular bacterial growth in macrophages. Blood 2008;112:866-874.

42 Nairz M, Theurl I, Ludwiczek S, Theurl M, Mair SM, Fritsche G, Weiss G: The co-ordinated regulation of iron homeostasis in murine macrophages limits the availability of iron for intracellular Salmonella typhimurium. Cell Microbiol 2007;9:2126-2140.

43 Van Zandt KE, Sow FB, Florence WC, Zwilling BS, Satoskar AR, Schlesinger LS, Lafuse WP: The iron export protein ferroportin 1 is differentially expressed in mouse macrophage populations and is present in the mycobacterial-containing phagosome. J Leukoc Biol 2008;84:689-700.

-44 Nairz M, Fritsche G, Brunner P, Talasz H, Hantke K, Weiss G: Interferon $\gamma$ limits the availability of iron for intra-macrophage Salmonella typhimurium. Eur J Immunol 2008; 38:1923-1936.

45 Ward PP, Paz E, Conneely OM: Multifunctional roles of lactoferrin: a critical overview. Cell Mol Life Sci 2005;62:2540-2548.
46 Legrand D, Elass E, Carpentier M, Mazurier J: Lactoferrin: a modulator of immune and inflammatory responses. Cell Mol Life Sci 2005;62:2549-2559.

47 Ward PP, Mendoza-Meneses M, Cunningham GA, Conneely OM: Iron status in mice carrying a targeted disruption of lactoferrin. Mol Cell Biol 2003;23:178-185.

48 Ward PP, Mendoza-Meneses M, Park PW, Conneely OM: Stimulus-dependent impairment of the neutrophil oxidative burst response in lactoferrin-deficient mice. Am J Pathol 2008;172:1019-1029.

49 Fischbach MA, Lin H, Liu DR, Walsh CT: How pathogenic bacteria evade mammalian sabotage in the battle for iron. Nat Chem Biol 2006;2:132-138.

50 Hantke K: Iron and metal regulation in bacteria. Curr Opin Microbiol 2001;4:172-177.

51 Jacobi CA, Gregor S, Rakin A, Heesemann J: Expression analysis of the yersiniabactin receptor fyuA and the heme receptor hemR of Yersinia enterocolitica in vitro and in vivo using the reporter genes for green fluorescent protein and luciferase. Infect Immun 2001;69:7772-7782.

52 Goetz DH, Holmes MA, Borregaard N, Bluhm ME, Raymond KN, Strong RK: The neutrophil lipocalin NGAL is a bacteriostatic agent that interferes with siderophore-mediated iron acquisition. Mol Cell 2002;10: 1033-1043.

53 Holmes MA, Paulsene W, Jide X, Ratledge C, Strong RK: Siderocalin (Lcn 2) also binds carboxymycobactins, potentially defending against mycobacterial infections through iron sequestration. Structure 2005;13:2941.

54 Flo TH, Smith KD, Sato S, Rodriguez DJ, Holmes MA, Strong RK, Akira S, Aderem A: Lipocalin 2 mediates an innate immune response to bacterial infection by sequestrating iron. Nature 2004;432:917-921.

55 Nelson AL, Barasch JM, Bunte RM, Weiser $\mathrm{JN}$ : Bacterial colonization of nasal mucosa induces expression of siderocalin, an ironsequestering component of innate immunity. Cell Microbiol 2005;7:1404-1417.

56 Draper DW, Bethea HN, He YW: Toll-like receptor 2-dependent and -independent activation of macrophages by group B streptococci. Immunol Lett 2006;102:202-214.

-57 Rodríguez N, Mages J, Dietrich H, Wantia N, Wagner H, Lang R, Miethke T: MyD88-dependent changes in the pulmonary transcriptome after infection with Chlamydia pneumoniae. Physiol Genomics 2007;30: 134-145.

58 Berger T, Togawa A, Duncan GS, Elia AJ, You-Ten A, Wakeham A, Fong HE, Cheung CC, Mak TW: Lipocalin 2-deficient mice exhibit increased sensitivity to Escherichia coli infection but not to ischemia-reperfusion injury. Proc Natl Acad Sci USA 2006; 103:18341839.
59 Saiga H, Nishimura J, Kuwata H, Okuyama M, Matsumoto S, Sato S, Matsumoto M, Akira S, Yoshikai Y, Honda K, Yamamoto M, Takeda K: Lipocalin 2-dependent inhibition of mycobacterial growth in alveolar epithelium. J Immunol 2008;181:8521-8527.

60 Martineau AR, Newton SM, Wilkinson KA, Kampmann B, Hall BM, Nawroly N, Packe GE, Davidson RN, Griffiths CJ, Wilkinson RJ: Neutrophil-mediated innate immune resistance to mycobacteria. J Clin Invest 2007; 117:1988-1994.

61 Fischbach MA, Lin H, Zhou L, Yu Y, Abergel RJ, Liu DR, Raymond KN, Wanner BL, Strong RK, Walsh CT, Aderem A, Smith KD: The pathogen-associated iroA gene cluster mediates bacterial evasion of lipocalin 2 . Proc Natl Acad Sci USA 2006;103:1650216507.

-62 Devireddy LR, Teodoro JG, Richard FA, Green MR: Induction of apoptosis by a secreted lipocalin that is transcriptionally regulated by IL-3 deprivation. Science 2001;293: 829-834.

63 Devireddy LR, Gazin C, Zhu X, Green MR: A cell-surface receptor for lipocalin $24 \mathrm{p} 3 \mathrm{se}$ lectively mediates apoptosis and iron uptake. Cell 2005;123:1293-1305.

64 Pietrangelo A: Hereditary hemochromatosis. Annu Rev Nutr 2006;26:251-270.

-65 Gardenghi S, Marongiu MF, Ramos P, Guy E, Breda L, Chadburn A, Liu Y, Amariglio N, Rechavi G, Rachmilewitz EA, Breuer W, Cabantchik ZI, Wrighting DM, Andrews NC, de Sousa M, Giardina PJ, Grady RW, Rivella $S$ : Ineffective erythropoiesis in $\beta$-thalassemia is characterized by increased iron absorption mediated by down-regulation of hepcidin and up-regulation of ferroportin. Blood 2007;109:5027-5035.

66 Tanno T, Bhanu NV, Oneal PA, Goh SH, Staker P, Lee YT, Moroney JW, Reed CH, Luban NL, Wang RH, Eling TE, Childs R, Ganz T, Leitman SF, Fucharoen S, Miller JL: High levels of GDF15 in thalassemia suppress expression of the iron regulatory protein hepcidin. Nat Med 2007;13:1096-1101.

-67 Templeton DM, Liu Y: Genetic regulation of cell function in response to iron overload or chelation. Biochim Biophys Acta 2003;1619: 113-124.

68 Hayden MS, Ghosh S: Signaling to NF-кB. Genes Dev 2004;18:2195-2224.

69 Ghosh S, Hayden MS: New regulators of NF$\kappa \mathrm{B}$ in inflammation. Nat Rev Immunol 2008; 8:837-848.

70 Bubici C, Papa S, Dean K, Franzoso G: Mutual cross-talk between reactive oxygen species and NF-кB: molecular basis and biological significance. Oncogene 2006;25:67316748.

71 She H, Xiong S, Lin M, Zandi E, Giulivi C,

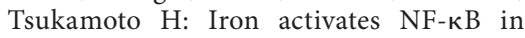
Kupffer cells. Am J Physiol Gastrointest Liver Physiol 2002;283:G719-G726. 
72 Chen L, Xiong S, She H, Lin SW, Wang J, Tsukamoto H: Iron causes interactions of TAK1, p21ras, and phosphatidylinositol 3-kinase in caveolae to activate IкB kinase in hepatic macrophages. J Biol Chem 2007;282:55825588.

73 Xiong S, She H, Takeuchi H, Han B, Engelhardt JF, Barton CH, Zandi E, Giulivi C, Tsukamoto H: Signaling role of intracellular iron in NF- $\mathrm{kB}$ activation. J Biol Chem 2003; 278:17646-17654.

74 Stocker R, Perrella MA: Heme oxygenase-1: a novel drug target for atherosclerotic diseases? Circulation 2006;114:2178-2189.

75 Ryter SW, Choi AM: Cytoprotective and anti-inflammatory actions of carbon monoxide in organ injury and sepsis models. Novartis Found Symp 2007;280:165-181.

-76 Soares MP, Seldon MP, Gregoire IP, Vassilevskaia T, Berberat PO, Yu J, Tsui TY, Bach FH: Heme oxygenase- 1 modulates the expression of adhesion molecules associated with endothelial cell activation. J Immunol 2004;172:3553-3563.

77 Seldon MP, Silva G, Pejanovic N, Larsen R, Gregoire IP, Filipe J, Anrather J, Soares MP: Heme oxygenase-1 inhibits the expression of adhesion molecules associated with endothelial cell activation via inhibition of NF$\kappa B$ RelA phosphorylation at serine 276. J Immunol 2007;179:7840-7851.

78 Kaelin WG Jr, Ratcliffe PJ: Oxygen sensing by metazoans: the central role of the HIF hydroxylase pathway. Mol Cell 2008;30:393402.
79 Cramer T, Yamanishi Y, Clausen BE, Förster I, Pawlinski R, Mackman N, Haase VH, Jaenisch R, Corr M, Nizet V, Firestein GS, Gerber HP, Ferrara N, Johnson RS: HIF- $1 \alpha$ is essential for myeloid cell-mediated inflammation. Cell 2003;112:645-657.

80 Peyssonnaux C, Datta V, Cramer T, Doedens A, Theodorakis EA, Gallo RL, Hurtado-Ziola N, Nizet V, Johnson RS: HIF-1 $\alpha$ expression regulates the bactericidal capacity of phagocytes. J Clin Invest 2005;115:1806-1815.

81 Zinkernagel AS, Johnson RS, Nizet V: Hypoxia inducible factor (HIF) function in innate immunity and infection. J Mol Med 2007;85:1339-1346.

82 Rius J, Guma M, Schachtrup C, Akassoglou $\mathrm{K}$, Zinkernagel AS, Nizet V, Johnson RS, Haddad GG, Karin M: NF- $\kappa$ B links innate immunity to the hypoxic response through transcriptional regulation of HIF- $1 \alpha$. Nature 2008;453:807-811.

83 Hartmann H, Eltzschig HK, Wurz H, Hantke K, Rakin A, Yazdi AS, Matteoli G, Bohn E, Autenrieth IB, Karhausen J, Neumann D, Colgan SP, Kempf VA: Hypoxia-independent activation of HIF-1 by enterobacteriaceae and their siderophores. Gastroenterology 2008;134:756-767.
84 Choi EY, Kim EC, Oh HM, Kim S, Lee HJ, Cho EY, Yoon KH, Kim EA, Han WC, Choi SC, Hwang JY, Park C, Oh BS, Kim Y, Kimm KC, Park KI, Chung HT, Jun CD: Iron chelator triggers inflammatory signals in human intestinal epithelial cells: involvement of p38 and extracellular signal-regulated kinase signaling pathways. J Immunol 2004;172: 7069-7077.

85 Markel TA, Crisostomo PR, Wang M, Herring $\mathrm{CM}$, Lahm T, Meldrum KK, Lillemoe KD, Rescorla FJ, Meldrum DR: Iron chelation acutely stimulates fetal human intestinal cell production of IL- 6 and VEGF while decreasing HGF: the roles of p38, ERK, and JNK MAPK signaling. Am J Physiol Gastrointest Liver Physiol 2007;292:G958-G963.

86 Choi EY, Park ZY, Choi EJ, Oh HM, Lee S, Choi SC, Lee KM, Im SH, Chun JS, Jun CD: Transcriptional regulation of IL- 8 by iron chelator in human epithelial cells is independent from NF- $\kappa \mathrm{B}$ but involves ERK1/2- and p38 kinase-dependent activation of AP-1. J Cell Biochem 2007;102:1442-1457.

87 Wang L, Johnson EE, Shi HN, Walker WA, Wessling-Resnick M, Cherayil BJ: Attenuated inflammatory responses in hemochromatosis reveal a role for iron in the regulation of macrophage cytokine translation. J Immunol 2008;181:2723-2731.

-88 Bullen JJ, Spalding PB, Ward CG, Gutteridge JM: Hemochromatosis, iron and septicemia caused by Vibrio vulnificus. Arch Intern Med 1991;151:1606-1609. 